\title{
CLOUD COMPUTING AS A TOOL FOR IMPROVING BUSINESS COMPETITIVENESS
}

\author{
Michał WIŚNIEWSKI \\ Faculty of Management, Warsaw University of Technology, Warsaw, Poland \\ e-mail: m.wisniewski@wz.pw.edu.pl
}

\begin{abstract}
This article organizes knowledge on cloud computing presenting the classification of deployment models, characteristics and service models. The author, looking at the problem from the entrepreneur's perspective, draws attention to the differences in the benefits depending on the cloud computing deployment models and considers an effective way of selection of cloud computing services according to the specificity of organization. Within this work, a thesis statement was considered that in economic terms the cloud computing is not always the best solution for your organization. This raises the question, "What kind of tools should be used to estimate the usefulness of the model cloud computing services in the enterprise?"
\end{abstract}

Keywords: cloud computing, data processing, opportunities, threats, service models, deployment models, the characteristics of cloud computing, innovation, estimating operating costs.

\section{Introduction}

One of the most important resources in the modern economy is information. Organizations depend on how fastly the data are accessed as the finished product, which is useful for decision making at all levels of management: strategic, tactical and operational level. At the same time, one of the problems of any organization is an excess of data. To effectively use the data, they must be collected, stored and processed with the support of tools such as: databases, data warehouses and BI systems. These tools allow fast access to data and present them in a transparent manner, which facilitates the work of, among others, managers.

Such a method of data processing requires an appropriate infrastructure. To begin with, special rooms designed for server rooms to the servers, disk arrays, backup copy systems, ending with the client stations should be maintained. All elements of the network generate costs for the organization at the time of purchase, during use and at a time when no longer useful. Software licenses also increase costs associated with the IT sector. Some organizations, especially small, are not able to meet these costs losing the opportunity to effective competition in the marketplace.

A remedy for the high costs of collecting and processing data within the organization may be to build virtual servers in the environment of cloud computing. There are companies that offer the opportunity to make use of hardware resources, operating platforms and software as a paid service via the Internet. The recipient is obliged to cover only the costs of purchase and maintenance of terminal stations, the Internet, cloud computing service costs and maintaining a minimum IT level dependent on the size and needs of the organization.

Looking at the phenomenon of cloud computing from the entrepreneur's perspective purchasing cloud computing service, a question arises whether this service should replace the collection and processing of data within the organization? What are the opportunities and risks, benefits and obligations coming out of the change of data processing?

This article presents the current state of knowledge on the concept of cloud computing and identifies questions that companies need to answer considering how to process the data within its own structure. Contrary to popular opinion, presented in literature and during conference speeches, the author believes that the current level of development of the cloud computing service cannot, in any case, be an alternative to the existing centers in the organizations. From the point of view of the entrepreneur, the most important indicator in choosing the method of data processing is the level of costs. Poorly chosen cloud computing service may result in increased costs, which negatively affect the competitiveness of the company.

\section{Cloud Computing}

\subsection{Definitions}

Cloud computing idea is not new. The concept of cloud computing is that IT resources, both hardware and software, are treated by the user as another medium such as electricity, gas or water. The recipient does not physically wonders where electricity comes from in his 
socket, just pays for the service. Most of us use cloud computing without being aware of it. A perfect example is the cloud computing e-mail service. The majority of users do not know where physically located e-mail messages are. Using the mailbox is done over the Internet, regardless of the location or device you are using; you always have access to e-mails. Therefore, the mail system supplier provides for us a service. The very concept of cloud computing has been used for the first time by Net Centricin 1997, so it is relatively new and still evolving, making it difficult to find one recognized by all definition in the literature.

According to IBM, cloud computing is a new model of IT use and processing style in which the business processes, applications, data and IT resources are delivered to users in the form of services [5, p. 145]. Another definition comes from the portal Wikipedia: Cloud computing is a processing model based on the use of services provided by external organizations. Functionality is understood as a service (which gives added value to the user) offered by the software (and the necessary infrastructure) [15]. The accepted definition of cloud computing in the scientific studies is that one developed by the National Institute of Standards and Technology (NIST) in 2011. According to the NIST, cloud computing is a model for enabling ubiquitous, convenient, on-demand network access to a shared pool of configurable computing resources (e.g. networks, servers, storage, applications and services) that can be rapidly provisioned and released with minimal management effort or service provider interaction. This cloud model is composed of five essential characteristics, three service models and four deployment models [10, p. 3].

All definitions consequently maintain that the object services are broadly defined IT resources. However, only the NIST definition emphasizes the factor that distinguishes cloud computing from other forms of outsourcing. It refers to the statement that the service is available on-demand, without necessary earlier orders or starting fee as it take place, for example, in the co-location model. Another important feature is the method of calculating fees. In contrast to classic forms of IT outsourcing, a cloud computing model provides a different solution where we pay for the resources actually used, and not for their declared use.

Looking at cloud computing from a purely technical point of view, this service is a blend of the known solutions in the provision of IT services, for example:
- Utility computing has usually envisioned some form of virtualization so that the amount of storage or computing power is available to individual business units or procedures. It also allows thorough settlement of the amount of processed data [13].

- Grid computing is defined as a hardware and software infrastructure that provides dependable, consistent, easily customizable and affordable access to computing resources [1, pp. $749-771]$. In contrast to utility, computing can also use the computing power of PC.

- Outsourcing is the transfer to external service providers in accordance with the provisions in the agreement (contract) repeated internal tasks of an organization related to the implementation of staff, equipment, facilities, equipment, technology and other resources and decision-making powers regarding their use [3, p. 3].

- Virtualization is characterized by abstract perception of hardware resources so that the resource can be activated to operate in various ways, regardless of its physical form or location [9, p. 856]. This allows more efficient use of existing hardware environment resources by modifying the characteristics of any resources, adapting them to user requirements.

- Distributed computing term conceals the technique of running calculations, enabling the sharing of computing resources such as: private computers, servers, etc., which is usually geographically dispersed. In a general sense, this technology means the data processing regarded as a public service. In other words, the client does not matter where the data are stored or which computer does the job. The customer can order the information or the calculations and results in the scope and time required [4, p. 37].

The functionality of these concepts allows for innovation within the model of business management. The availability of IT resources on demand and bearing the charges for the actually used resources allows you to change the cost structure of the organization. It leads to the reduction of the group cost classified as capital expenditures (CAPEX) $)^{1}$ and increasing of operating

\footnotetext{
${ }^{1}$ CAPEX- expenditures allocated to buy fixed assets such as equipment, e.g. IT equipment.
} 


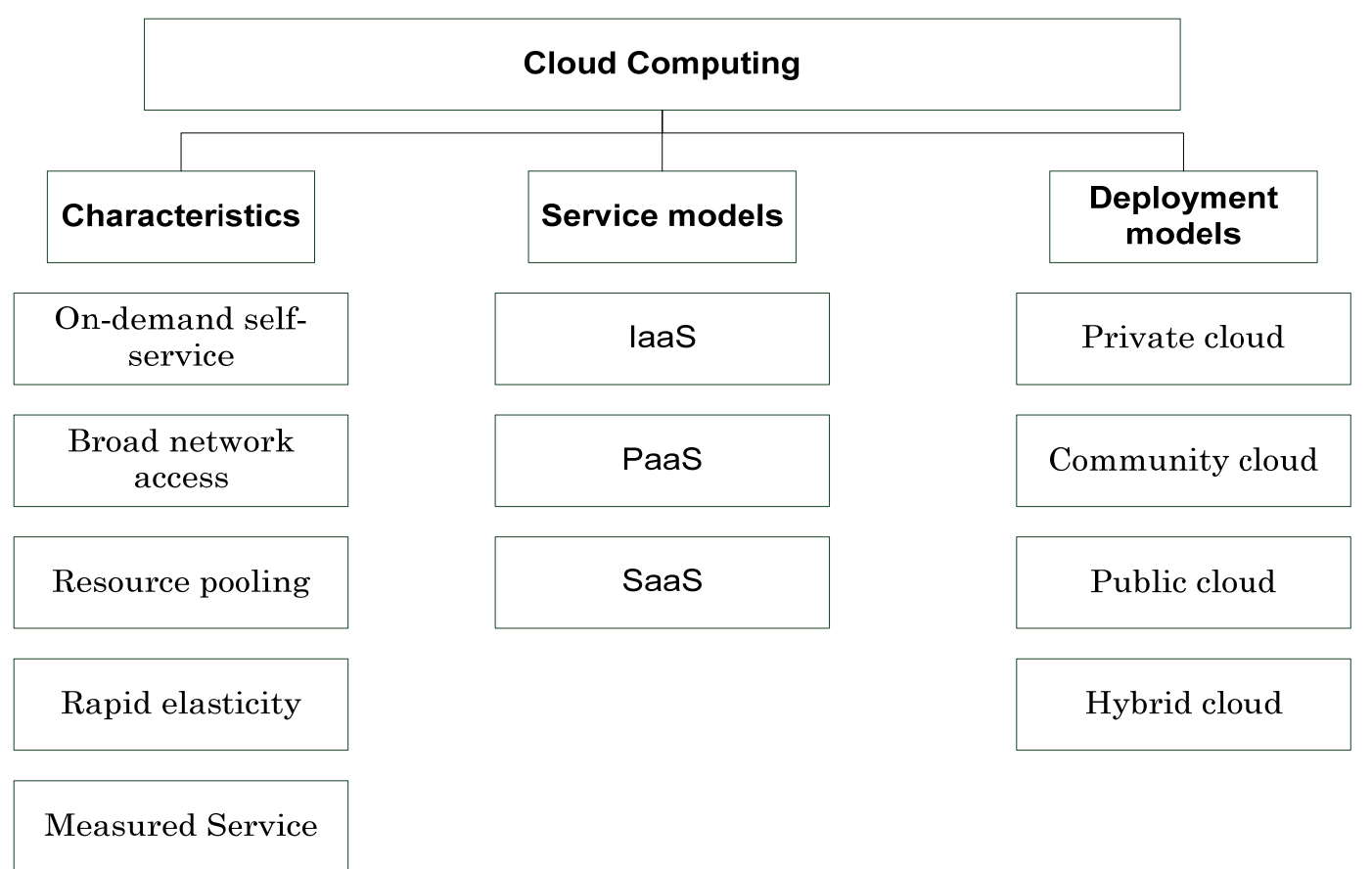

Figure 1. Concept of cloud computing services (source: own elaboration)

expenditures (OPEX). ${ }^{2}$ This means that the barrier related to the purchase of IT infrastructure or the necessary high costs of the rent in advance ceases to exist.

A company using the cloud computing model bears the charges on an ongoing basis, as part of the operating costs.

The basic premise of the cloud computing is the availability of services delivered over the Internet or intranet, based on a model composed of five essential characteristics, three service models and four deployment models shown in Figure 1.

Organizations taking the decision to use cloud computing services do not reflect that kind of cloud is to let suitable. This leads to inefficient use of IT, and in extreme cases, to increase in the operating costs of those departments. To avoid such situations, we must understand the advantages and disadvantages of the different types of clouds. For this purpose, the elements shown in Figure 1 will be discussed in more detail.

\subsection{Essential Characteristics}

- On-demand self-service - a consumer can unilaterally configure provision computing capabilities, such as server time and network storage, as needed au-

\footnotetext{
${ }^{2}$ OPEX - is the sum of a business's operating expenses for
} a period of time. tomatically without requiring human interaction with each service provider.

- Broad network access - capabilities are available over the network and accessed through standard mechanisms that promote use by heterogeneous thin $^{3}$ or thick client ${ }^{4}$ platforms (e.g. mobile phones, tablets, laptops and workstations).

- Resource pooling - the provider's computing resources are pooled to serve multiple consumers using a multi-tenant model, with different physical and virtual resources dynamically assigned and reassigned according to consumer demand.

- Rapid elasticity - capabilities can be elastically provisioned and released, in some cases automatically, to scale rapidly outward and inward commensurate with demand.

\footnotetext{
3 Thin client is a computer or specialized device (computer terminal) and related software client, enabling support for applications created in the client-server architecture. A thin client occurs as independent of the supported application server (the change does not involve having to change client software). Another advantage is the low demand for processing power [15].

${ }^{4}$ Thick client is a computer in client-server architecture or networks. It refers to the user's workstation, which is equipped with a set of peripherals, operating system installed and set of applications. Programs are executed directly and autonomously at the station does data processing and data exchange with the user and other computers on the network. Data are stored on the server side. [15]
} 
Measured service - cloud systems automatically control and optimize resource use by leveraging a metering capability at some level of abstraction appropriate to the type of service (e.g. storage, processing, bandwidth, computing power, RAM and active user accounts). It provides transparency for both the provider and consumer because of the pay-per-use structure.

The author refers to the definitions of the characteristics recommended by the National Institute of Standards and Technology $[9$, p. 2]. These characteristics are the pillars of what is called cloud computing. The resignation of one element will affect the whole cloud computing model. The first four characteristics are responsible for the flexibility of the solution in terms of the availability of IT resources. Measured service allows charging customers according to usage.

\subsection{Service Models}

Software as a service (SaaS) is defined as the capability provided to the consumer to use the provider's applications. Recipient decides which package of programs offered by the supplier will serve his needs. The SaaS model allows entrepreneurs to pay only for the software features they actually run and charge for actual time of use. The software package dedicated to the individual customer operates, maintaining an adequate level of data security, in addition to other software packages on a shared server. The client shall determine the number of employees who have access to the shared programs. The number of employees and the actual usage are the basis for calculating the subscription fee. Software as a Service removes the need to handle the installation, set-up and often daily up keep; reduces cost of implementation of new software; gives an advantage of speed implementation and access to the latest software. Because the software is hosted remotely, users do not need to invest in additional hardware and purchasing software licenses.

Platform as a service (PaaS) is defined as a computing platform being delivered as a service to the customer delivering via the virtual work environment, among others, operating systems such as Windows Azure created by Microsoft or Google's Chrome OS. Customers can use the infrastructure and development tools hosted by a service provider to build their own applications and working environment. This model deploys onto the cloud infrastructure consumer-created or acquired applications without the need to purchase hardware or software installation. PaaS service is available to any user regardless of the used end station. In addition, the client is not involved in the maintenance of the operating system itself, updating, backup, etc. The customer is to only maintain and take care of selfcreated or installed applications. The advantages of using PaaS services include: no need to purchase a commercial license for operating systems, no need to update operating environments by the service provider, access to the latest versions of operating systems at no additional charge and the possibility of using the work environment on different computers.

Infrastructure as a service (IaaS) is to provide the hardware understood as RAM, disk space, computer performance, etc. over the Internet in the form of virtual resources scaled according to the needs of the recipient. Resources that are the supplier property will be virtually separated within the physical devices under his control. The owner of the operating environment, installed programs and processed data in this service model, is the recipient. This implies a need for maintenance and updating of software. The advantages of using IaaS services removes the hardware purchase costs and maintenance costs of network devices, provides the ability to quickly expand virtual hardware resources (if necessary) and the ability to reduce virtual hardware resources, and the saving of office space determined by the lack of need for a complex server.

Table 1 presents a summary of the described cloud computing services and organizes issues of ownership and responsibility for the individual elements as the subjects of services. Sign (-) indicates that the control of the resource has the customer, sign $(+)$ indicates that the resource is under provider control, while the sign $(+/-)$ indicates that the resource is under common control of both entities.

Table 1 presents the distribution of responsibility for IT infrastructure between the provider and the recipient. In each of the listed cases, the company as a customer bears the responsibility for the data. Responsibility for infrastructure differs, depending on the variant. Customer must reckon with the fact that the greater the responsibility is shifted to the provider, the greater will be the cost of the service. 
Table 1. Distribution of control in models of cloud computing services (source: [6, p. 6])

\begin{tabular}{|c|c|c|c|c|}
\hline Specification & Classic model & IaaS & PaaS & SaaS \\
\hline Data & - & - & - & - \\
\hline Applications & - & - & - & + \\
\hline Operating environment & - & - & + & + \\
\hline Virtual machine & - & $+/-$ & + & + \\
\hline Servers & - & + & + & + \\
\hline Data warehouses & - & + & + & + \\
\hline Network & $+/-$ & + & + & + \\
\hline
\end{tabular}

\subsection{Deployment Models}

Public Cloud is the most popular and least engaging customer types of cloud computing. The cloud infrastructure is provisioned for open use by the general public. The public users may pay fixed monthly fees for services they utilize. Examples of companies offering this type of service include Google, Microsoft, Amazon and leading Polish groups: Onet.pl Group and ATM SIS.A. There are also free versions of public clouds such as already mentioned mailboxes. Google has gone one-step further and made users of Gmail mailboxes tools to create a network of office documents, Web pages and virtual disks. Another feature of the public cloud, whose presence should be aware of, is the fact that services can be provided by more than one entity, e.g. one company provides virtual hardware, another operating platform, and even other applications used by the customer.

Taking everything into account, Public Cloud is a form of cloud computing, which is the most convenient for the customer. Recipient procures certain services, pays a fee and through Internet connection which is required in this case, starts using the service. Public Cloud combined with IaaS, PaaS and SaaS package services is most beneficial for the company. Using this combination frees the business from having to purchase, service and maintain hardware and to pay for software licenses. It saves office space, electricity and takes advantage of many other benefits that will be presented later in the article.

Why do not all benefit from this kind of technology? There are many existing reasons in the literature but from the business point of view the most important seems to be a concern for safety data processing, especially classified information. Therefore, security consideration may be substantially responsible for the concept of private, common and hybrid clouds.
Private cloud is a solution to the problems of data security in cases where the company does not want or cannot process them outside fully controlled by them data centers. More specifically, Private Cloud solves legal issues. Physical security of data and protection against hacker attacks are a separate issue.

Private cloud infrastructure is operated solely for a single organization whether managed internally or by a third-party and hosted internally or externally. From a technical point of view, the purchase and construction of hardware infrastructure private cloud is not much different from the classic server. The difference lies in the layer of software that runs on the available hardware.

It is easy to notice that this type of solution is not available for any organization. Undertaking a private cloud project requires a significant level and degree of engagement and requires the organization to have sufficient funds and skilled employees, which is unavailable for many companies, such as in the SME. Therefore, these solutions are typically used by large companies where the scale of projects linked to the legal protection of data processed is economically justified.

However, the question is if this type of private enterprise has a chance to actually provide a higher level of security against hackers or natural disasters that can lead to irreversible data loss. For large organizations, such as multinational corporations, where there are adequate financial resources, perhaps it does. In other cases, companies are notable to provide better security than external suppliers.

Cloud computing providers invest in a giant cloud data centers, often costing \$ 500 million or more. In 2008, Google spent on the construction of data centers of $\$ 2.3$ billion. Economies of scale are the key factor applied by cloud providers. Huge orders for equipment, energy, as well as strategic location of data centers 
around the power plant, data center operators can count on big discounts of $60 \%$ and more. An example is Amazon, which in 2008 paid about 90 million dollars for 50 thousand SGIRackable servers. In normal trading, they cost 215 million dollars. [12]

We can likely find out that a single organization is notable to guarantee a higher level of security for their data due to the funds invested by cloud service providers, economies of scale determined by the amount of customers and duplication of data centers in different parts of the country or the world. In addition, there are issues related to the experience of employees in safety and innovation and modernity solutions.

In conclusion, private cloud is technically and costly neighboring the classical data processing. The whole process and the responsibilities and costs remain at the client side. However, private cloud gains more efficient use of network resources (servers, disk arrays, etc.), and retains control of classified data what is important for the current legislation reasons.

Community cloud is defined by NIST as infrastructure provisioned for exclusive use by a specific community of consumers from organizations that have shared concerns (e.g. mission, security requirements, policy and compliance considerations). It may be owned, managed and operated by one or more of the organizations in the community, a third party, or some combination of them, and it may exist on or off premises [10, p. 3]. Thus, community cloud is in a sense a kind of private cloud connecting entities with a similar profile that agree to share technical resources and, in some cases, the data. Organizations that cannot afford to build a private cloud are investing in community cloud, and because the law does not allow for the processing of data centers that are not under control of the company. As the number of participants in such a project is much smaller than in the case of public cloud, part of the economic benefits resulting from economies of scale is not possible to achieve. However, compared with the private cloud construction and maintenance the costs are much lower.

Hybrid cloud is a composition of two or more distinct cloud infrastructures (private or public) where some of the data are processed in the public cloud and the classified data in the private cloud. Hybrid cloud seeks to deliver the advantages of limiting the capacity of private clouds, which allows operating in accordance with the law and potential cost saving which is smaller than the costs of management data of public clouds.
Despite the deployed variant of cloud computing services, the main problem arises from the need for technological standards. This leads to a situation where the client has limited ability to change service provider. This carries a risk of dependence on single supplier companies, who may impose inflated price of the service.

\subsection{Selection of cloud computing services}

The main motive in favor of the deployment of cloud computing solutions in organizations both private and public is economic considerations. Enterprises processing the data in a classical way must themselves take care of all the related aspects of the process such as: security, modernization of IT infrastructure, and software licenses. Cloud computing provides many opportunities for cost savings to companies and individual users. It should be noted, however, that in its current form, the cloud computing is not a perfect solution, and as each new solution has its drawbacks, it eliminates part of the known risks, but also creates new ones.

The authors of the various studies agree that the main advantages of cloud computing include saving, performance, scalability, availability, reliability, time of implementation of new functionality. Launching new Google Apps services at the University of Warsaw is an example of a much faster launch of IT services. Within three months of the service running the UW students were provided with the access to email, storage of documents on the web, creation web pages, blogs and the use of office software package together with the transfer of existing student mailboxes from the university server [14]. The launch of a new multimedia service newspaper Rzeczpospolita may serve as a second example. The site was built entirely in the cloud within three weeks. For comparison, the construction time of the same service in the bar form would take from 6 weeks to 4 months [6, pp. 20-22].

Cloud computing security was not listed deliberately among the advantages because the opinions differ on this matter. Some authors consider cloud solutions far safer than traditional protection mechanisms what in view of applied relevant procedures and technical solutions should be considered as more effective. On the other hand, the privacy and legislation cannot be underestimated. 


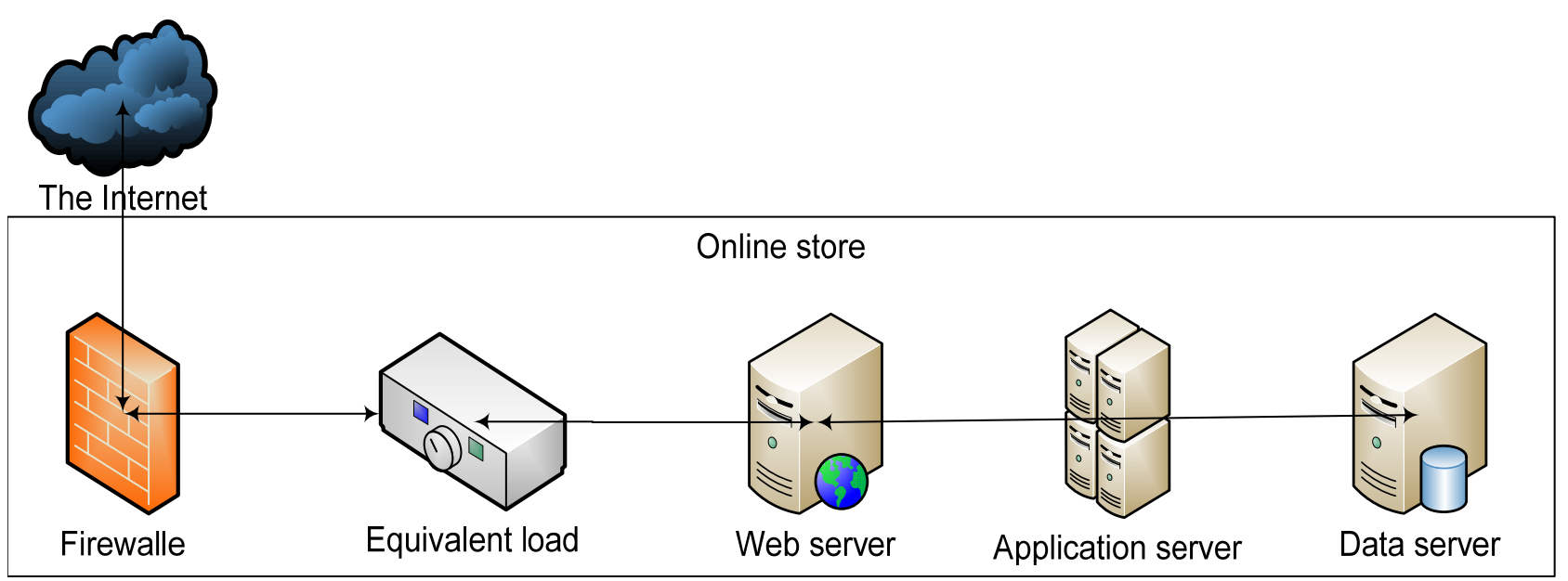

Figure 2. Elements of the IT infrastructure of the analyzed online store (source: own elaboration)

Users storing and processing data in the cloud do not always know where their data are physically located and who and on what basis has access to them. Data breach is a big concern in cloud computing. Customers worry if provider cloud computing services informs them about any breach of security in their data centers. In addition, some companies offering cloud computing services has registered their offices outside the European Union and are not subjected to EU law, which may lead to lower standards of data security.

Disadvantages associated with uncertainties about the safety of the cloud computing services are multiplied, but limitations as dependence on software providers, the lack of readiness of employees to use the cloud, IT specialists' reluctance to potentially dangerous changes to their employment, internet links with insufficient bandwidth.

Considering the advantages and disadvantages, opportunities and threats related to the processing of data in the cloud should compute the type of cloud (public, private, shared, hybrid) and the range of services offered should be taken into account. Most of these benefits are available if the company chooses IaaS, PaaS, SaaS models. The adoption of these models is most profitable for the company providing more flexibility, lower costs and ease of use. In contrast, it is not so evident in the case of private cloud. In this case, the solution, in terms of costs and responsibilities, differs slightly from the classical data processing solutions. Because the data center is under the control of the company it dissolves the problem associated with legal provisions.
How to determine whether transition from the classical model to cloud computing model is cost-effective and which set of cloud services, determined by a combination of available service models, deployment models and types of clouds, is the best for the organization?

It seems that in order to answer this question, it is necessary to develop a method of balancing the costs and expected benefits of both classical and cloud computing solutions. Such a method should take into account not only the cost of construction and equipment of the server but also the speed of deployment of new functionalities, which have been shown on the example of a Rzeczpospolita newspaper multimedia service, the cost of qualified staff employing, operating costs and the costs of disposing of waste or unnecessary IT equipment.

\section{Case Study}

This case study demonstrates how company is planning within existing operations the creation of an online store selling sporting goods. The online store activities were to be maintained for three consecutive years. After this time, the decision to continue or discontinue operations might be made. The company has already created the necessary IT infrastructure including its own data center and qualified staff. To start a new project, a company must purchase additional hardware. All new hardware components are shown in Figure 2. To ensure continuity of service availability and to reduce outage duration each of the elements will be duplicated as presented in Figure 2. Project management assumes a stable IT infrastructure load without load surges. 
Table 2. Cost of purchasing new IT infrastructure elements needed for launching an online store (source: own elaboration)

\begin{tabular}{|c|c|c|c|}
\hline Specification & Unit price & $\begin{array}{c}\text { Number } \\
\text { of items }\end{array}$ & Internal solution \\
\hline Firewall & 4000 & 2 & 8,000 \\
\hline Equivalent load & 14000 & 2 & 28,000 \\
\hline Network server & 8500 & 2 & 17,000 \\
\hline Application server & 8500 & 2 & 17,000 \\
\hline Data server & 8500 & 2 & 17,000 \\
\hline & - & - & 87,000 \\
\hline
\end{tabular}

Free software will be used to minimize the building costs of an online store. Necessity to purchase a new hardware and the uncertainty whether the shop will continue to exist after the assumed time begs the question. The question may yet be raised in another case whether the cost of new IT equipment and launching of the project in the company's data center will be profitable. Is the lease of virtual stores an advantageous solution in the cloud computing formula?

Project management deciding to launch an online store in their own data center must bear the costs presented in Table 2.

The cost of purchasing the necessary elements of the IT infrastructure for launching an online store in their own data center is at the level of about 87,000 PLN. Assuming a three-year period of the project, the cost is 2416,67 PLN per month. The total amount must be paid in advance. The calculation applies only to the purchase of necessary new infrastructure elements. Costs not taken into account include:

- power supply of purchased equipment,

- cooling of purchased equipment,

- server rack space,

- internet connection (for example, an additional link $10 \mathrm{Mb}-3000 \mathrm{PLN}$ per month),

- staff remuneration (administrators and technicians),

- staff training.

These cost categories are not included in further analysis because they are already paid by the company, which maintains its own data centers. The increase in operating costs due to the purchase of new IT equipment makes only small part of total costs and would be considered insignificant. Therefore, we are not going to analyze those costs any more.

Summing up the cost of launching, an online store in the enterprise data center, the adopted assumptions that month about 2,400 PLN at a three-year term adds up to about 87,000 PLN. However, there is a possibility that after this planned period the project will be liquidated as unprofitable. If this happens, the company remains with unused network equipment that should be maintained or to bear the costs of disposal.

An alternative solution to eliminate the problem of unnecessary IT equipment is to launch an online store in the cloud computing environment. Starting a project within cloud computing formula offers cost savings because of "pay-as-you-go" services with no contracts, and often no sign-up fees and just we pay for what we use, e.g. RAM, CPU, hard drives.

A company to run an online store in cloud computing instead of buying physical hardware purchases its virtual counterparts. Table 3 presents a summary of virtual instances offered by Amazon, Microsoft and Polish company. Unlike Amazon and Microsoft, Polish company does not offer predefined instance but allows configuration of a virtual server according to client's needs. In case of Amazon Medium Instance, it corresponds to the physical server needed for the planned creation of an online store. And Microsoft Large Instance meets the requirements of the project. To ensure the comparability of virtual instances for Polish company, identical parameters for virtual servers as for the selected instance Amazon shall be adopted. Instances replace virtual IT infrastructure elements such as a network server, application server and data server. It is necessary to take out six virtual instances to replace six physical servers of assumed IT structure. To build a comprehensive IT infrastructure, a service must be purchased to replace the firewall and server load equivalent. Table 4 gives the monthly rental cost of such services in comparable companies assuming that the services are still available for all rented instances. 
Table 3. Summary of virtual instances offered by Amazon, Microsoft and Polish company (source: [2, p. 150, 7, p. 84], Polish company offer)

\begin{tabular}{|c|c|c|c|c|}
\hline Specification & RAM (GB) & Processors & Data warehouse (GB) & Platform (bits) \\
\hline \multicolumn{5}{|l|}{ - Amazon } \\
\hline - $\quad$ small & 1.7 & $1.2 \mathrm{GHz}$ & 160 & 32 \\
\hline - medium & 7.5 & $4 \times 1.2 \mathrm{GHz}$ & 850 & 64 \\
\hline - large & 15 & $8 \times 1.2 \mathrm{GHz}$ & 1690 & 64 \\
\hline \multicolumn{5}{|l|}{ - Microsoft } \\
\hline - extra small & 0.768 & $1 \mathrm{GHz}$ & 20 & 32 \\
\hline - small & 1.75 & $1.6 \mathrm{GHz}$ & 225 & 32 \\
\hline - medium & 3.5 & $2 \times 1.6 \mathrm{GHz}$ & 490 & 64 \\
\hline - large & 7 & $4 \times 1.6 \mathrm{GHz}$ & 1000 & 64 \\
\hline - $\quad$ extra large & 14 & $8 \times 1.6 \mathrm{GHz}$ & 2040 & 64 \\
\hline \multicolumn{5}{|l|}{ - Polish firm } \\
\hline - client configuration & $\mathrm{n} \times 1$ & $\mathrm{n} \times 1 \mathrm{GHz}$ & $\mathrm{n} \times 1$ & $32 / 64$ \\
\hline
\end{tabular}

Table 4. Summary of cost of services

(source: [7, s. 84-86], Polish company offer)

\begin{tabular}{|c|c|c|}
\hline Specification & Virtual VPN & Virtual load balancers \\
\hline Amazon & 622,00 PLN & 72,00 PLN \\
\hline Microsoft & 600,00 PLN & 94,00 PLN \\
\hline Polish firm & 300,00 PLN & 15,00 PLN \\
\hline
\end{tabular}

Table 5. Simulation of the transfer and storage of data costs (source: [7, pp. 84-86], Polish company offer)

\begin{tabular}{|c|c|c|}
\hline Specification & Data transfer & Data storage \\
\hline Amazon & 32,50 PLN & 855,00 PLN \\
\hline Microsoft & 35,00 PLN & 850,00 PLN \\
\hline Polish firm & 90,00 PLN & 900,00 PLN \\
\hline
\end{tabular}

Estimated costs of building an online store in the cloud computing formula must include costs resulting from the provision of IT infrastructure and additional costs resulting from launching the project outside of their own data center. They include data storage and data transfer. Table 5 shows the costs of these services in the analyzed companies. The objectives of the simulated costs are:
- data transfer not exceeding 1TB per month,

- stored data not exceeding 2TB.

Table 6 summarizes all categories of costs for launching an online store, both in their own data center and hiring the necessary IT infrastructure in the cloud computing formula. 
Table 6. Total costs

(source: own elaboration)

\begin{tabular}{|c|c|c|c|c|}
\hline Specification & $\begin{array}{l}\text { Cost of own } \\
\text { launching }\end{array}$ & $\begin{array}{l}\text { Cloud computing } \\
\text { cost Amazon }\end{array}$ & $\begin{array}{l}\text { Cloud computing } \\
\text { cost Microsoft }\end{array}$ & $\begin{array}{l}\text { Cloud computing } \\
\text { cost Polish firm }\end{array}$ \\
\hline Virtual VPN/firewall & 222, 22 PLN & 622,00 PLN & 600,00 PLN & 300,00 PLN \\
\hline Equivalent load & 777, 78 PLN & 72, 00 PLN & 94, 00 PLN & 15,00 PLN \\
\hline Virtual network server & 472,22 PLN & \multirow{3}{*}{2172,00 PLN } & \multirow{3}{*}{6498,87 PLN } & \multirow{3}{*}{8913,00 PLN } \\
\hline Virtual application server & 472,22 PLN & & & \\
\hline Virtual data server & 472, 22 PLN & & & \\
\hline Data transfer & 0,00 PLN & 490, 00 PLN & 35,00 PLN & 290, 00 PLN \\
\hline Storage of data & 0,00 PLN & 855,00 PLN & 850,00 PLN & 900,00 PLN \\
\hline Total monthly costs & 2416,67 PLN & 4211,00 PLN & 8 077, 87 PLN & 10 418, 00 PLN \\
\hline Total cost after 3 years & 87 000, 00 PLN & 151596,00 PLN & 290803,31 PLN & 375 048, 00 PLN \\
\hline
\end{tabular}

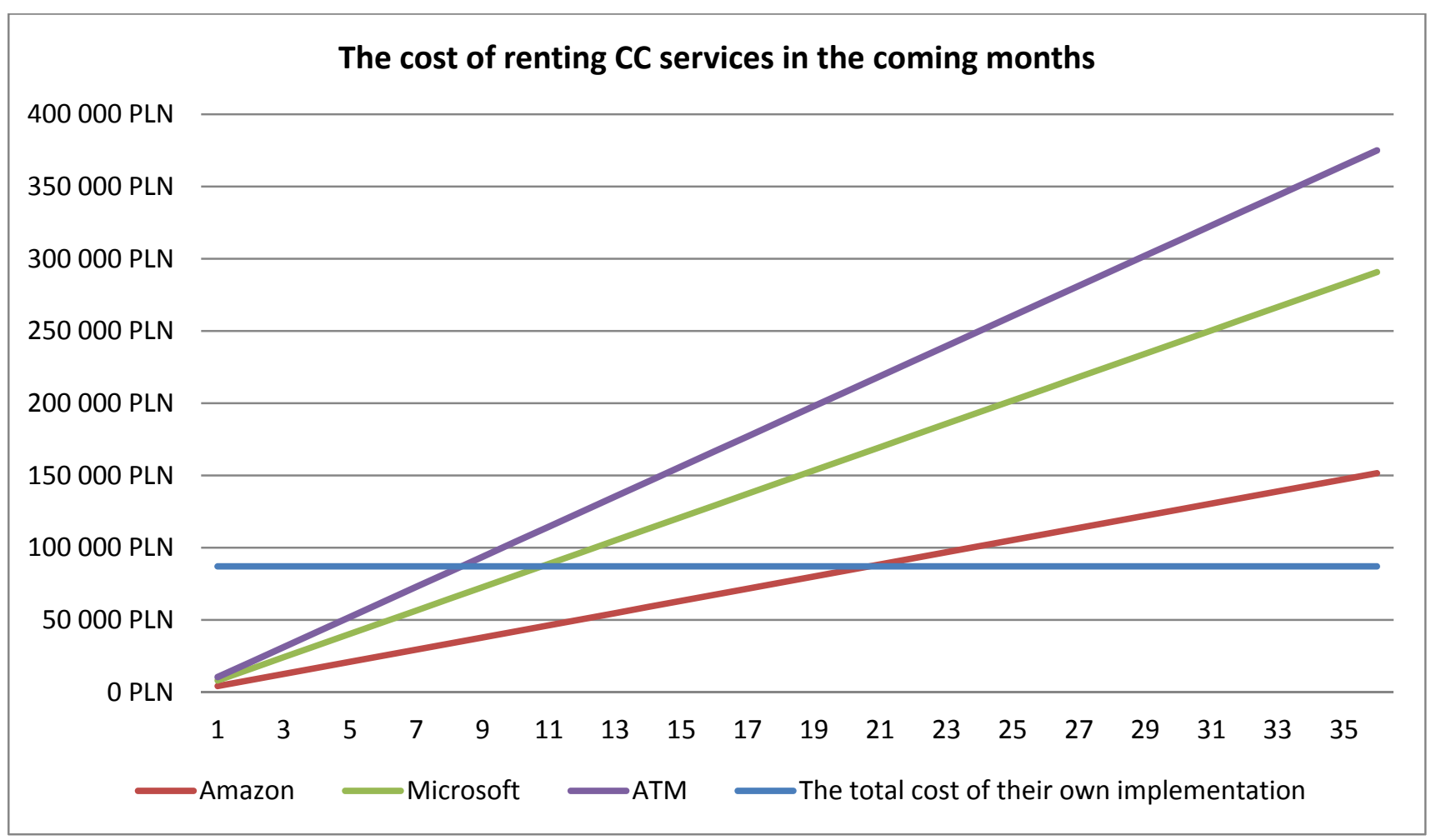

Figure 3. The costs of renting cloud computing services in the coming months (source: own elaboration)

Figure 3 shows the change in the data in Table 6 during 36 months operating of online store. Graph analysis reveals that the assumed period and IT infrastructure requirements for launching an online store in cloud computing formula must be considered as uneconomic. The total cost of provisioning additional hardware for the project to be launched in their own data center is generally estimated at 87,000 PLN. This amount is exceeded by all the analyzed cloud providers' bids.
In the case of Amazon, it occurs after 21 months, Microsoft after 11 months and Polish company after 9 months.

Chart analysis draws attention to the time of service operation, which turns out to be very important and must be included in a proposed method for the selection of cloud computing services for the organization. 


\begin{tabular}{|c|c|c|c|c|}
\hline $\begin{array}{c}\text { Phase I } \\
\text { Qualitative evaluation }\end{array}$ & \multirow{3}{*}{$\begin{array}{l}\text { Designation } \\
\text { of solution set }\end{array}$} & $\begin{array}{c}\text { Phase II } \\
\text { Quantitative } \\
\text { evaluation }\end{array}$ & \multirow{3}{*}{$\begin{array}{c}\text { Comparison } \\
\text { of variants }\end{array}$} & $\begin{array}{l}\text { Phase III } \\
\text { Decision }\end{array}$ \\
\hline $\begin{array}{c}\text { Identification } \\
\text { of company needs }\end{array}$ & & $\begin{array}{c}\text { Evaluation } \\
\text { of obtained cloud } \\
\text { computing solutions }\end{array}$ & & \multirow[b]{2}{*}{ Decision } \\
\hline $\begin{array}{l}\text { Gathering data about } \\
\text { the possibilities } \\
\text { offered by cloud compu- } \\
\text { ting vendors }\end{array}$ & & $\begin{array}{c}\text { Evaluation } \\
\text { of classical solutions }\end{array}$ & & \\
\hline
\end{tabular}

Figure 4. Model making decisions on the use of cloud computing in the enterprise (source: own study)

The discussed example also brings some assumptions and simplifications that had to make it more understandable. All these elements are integral part of a general methodology of the proceedings.

There are many combinations of these factors as well as factors affecting the viability of the use of a specific enterprise in the cloud computing including the following:

- status of the business (start or continuation),

- having or not their own data center,

- having or not the skilled workers of IT department,

- the complexity of the IT infrastructure,

- operation time of the projects,

- presence or absence of high loads surges of IT infrastructure,

- applied software.

The multiplicity and diversity of decision-making areas according to the author determine the need to develop a methodology clearly defining the criteria that should be taken into account, and present a method to deal with the process of collecting the necessary data and making decisions. Previous analysis of literature sources did not reveal the existence of such a method.

\section{$4 \quad$ Research methods}

As a result of presented cloud computing services in the previous chapters, the author proposes a threetier cloud computing model of decision-making on the use of outsourcing IT services in the enterprise (see Figure 4).

The proposed first stage of the procedure involves two elements. First, the company needs to determine their requirements for IT infrastructure. Such a document should include information about the assumed minimum and maximum demands: main memory, disk storage, computer performance,

Internet bandwidth, load estimation infrastructure at critical moments and the duration of such a load along with its frequency, etc. Identification of the necessary data by many businesses, especially in the sector of small and medium-sized companies, can make an insurmountable barrier. Therefore, the proposed approach is to develop a model document that will contain the necessary parameters and guidelines to support the estimation process.

The second element of the first stage should include the collection of data on the possibilities offered by the cloud computing. Here, it is also advised to develop a set of basic information about the cloud computing services, updating them together with the market development, and sharing them with companies considering the implementation of cloud computing..

Finally, the comparison of the two sets of information should lead to a selection of those solutions offered by the cloud computing, which meet the company requirements. 


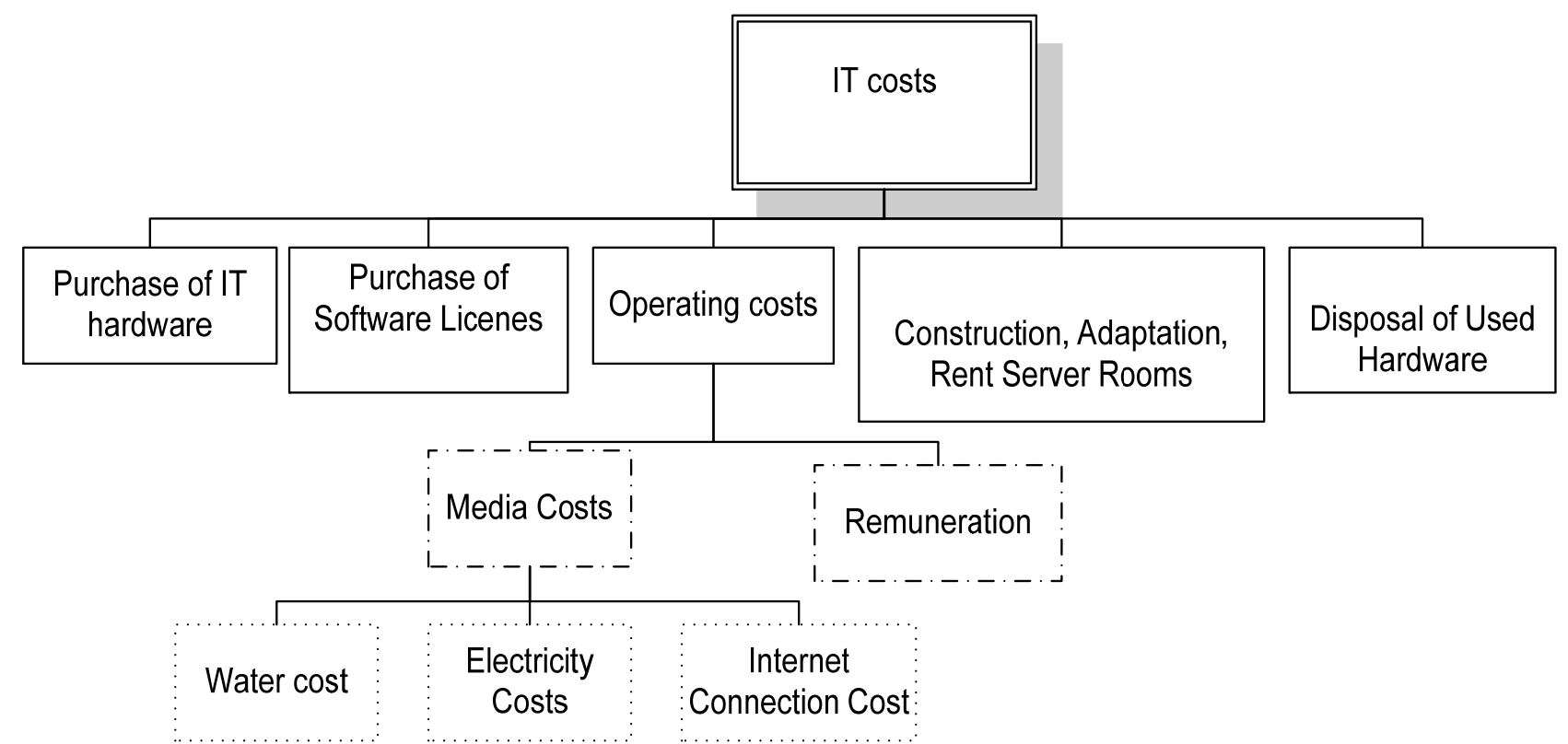

Figure 5. Diagram of the costs associated with IT infrastructure (source: own elaboration)

In the second stage, the company having a set of possible solutions meeting their requirements and taking into account various vendors should proceed to the valuation of the cloud computing solutions. Then, the cost of launching the necessary infrastructure within the organization should be specified. Estimating the cost of deploying IT infrastructure in-house, a company should take into account several aspects: the cost of purchasing IT equipment, the cost of construction or adaptation server rooms, operating costs, infrastructure maintenance, waste disposal costs of IT equipment and other devices of the server rooms such as air conditioners or the time needed for IT infrastructure to support the project. Figure 5 presents a diagram of IT department costs.

After obtaining the necessary quantitative data, the company managing board should come to a decision about the application of one of the available solutions. It should be emphasized that decision making guided by the criterion of the lowest price is not always the right one. One can imagine a situation in which the difference in costs between classical data processing and cloud computing services might be so insignificant that taking into account the development and probably the cost reduction in cloud computing services, the company decides to outsource IT infrastructure.

The application of presented approach should be determined on the operating expenses of IT infrastructure used in the enterprise. Unfortunately, the lack of meth- ods for estimating such costs makes it very difficult. Institute for Market Economics in its report in 2011 estimated that $80 \%$ [8, p. 29] of IT budgets are spent on maintaining current IT infrastructure; however, the data may vary in companies and should be verified.

This brings up the research questions:

1. What is the level of operating costs incurred for the maintenance of the IT infrastructure of the organization?

2. What is the break-even point for the maintenance of own IT infrastructure?

3. What is the trend in costs of cloud computing services and when the cost is low enough that it would be uneconomic to maintain their own IT infrastructure?

Taking an attempt to answer these questions, the author proposes a two-stage study. The first step assumes the development of a questionnaire addressed to all employees of the company. The purpose of the survey is to collect information about IT equipment (corporate and private) used by employees and the time allocated to the usage of each device. The second stage of the study should determine the level of energy and water (in the case of air conditioners) consumption per each unit of IT infrastructure. For that purpose, necessary will be the use of special measuring equipment's connected to every device separately. Collected survey data, media consumption measurement data and employee remunerations allow the author obtaining a nec- 
essary knowledge about the level of operating costs of maintaining the IT infrastructure of a company.

Gathering data on the media consumption from the suitable number of organizations helps to determine the average values for different types of IT infrastructure devices what significantly will facilitate the application of the method in organizations, which will not be in a position to finance the second stage of the investigation.

In conclusion, the proposed method consists of three steps. The input to the first stage is information about the internal needs of the company and details about the capabilities of cloud computing services providers. In this way, it becomes possible to reject those solutions that do not meet the organization data processing requirements. Solutions that meet the company requirements together with the knowledge of the costs of the various solutions are making a set of input data for the second stage of the proceedings. Thus, a ranking of possible solutions structured by cost comes into being. The third stage is a decision-making process that attends to imply the best solution in the company.

\section{Summary}

Referring to the question posed in the introduction, it should be noted that the cloud computing service in its current form is not the most advantageous solution for any organization. Cloud computing reliability is not guaranteed in matters relating to security, which is of great importance for banking and insurance companies. Another major limitation is the data transfer rate through the Internet that prevents the use of computing potential power delivered by large data centers. On the other hand, cloud computing solutions perfectly suit the cases where data should be made publicly available, e.g. multimedia services. Then, we can enjoy the full benefits of what brings cloud computing.

Considering the limitations and imperfections of current cloud systems, it appears advisable to develop a quantitative method to determine whether the use of cloud computing or the transition from the classical model of data processing into one of the cloud computing models is profitable. It should be clear that cloud computing service is not homogeneous and must be considered in the context of a specific deployment model, service model and type of cloud. It is recommended that for such definite matrix, areas defined by three dimensions should be developed for each a set of advantages and disadvantages, opportunities and threats to the organization. A SWOT analysis can be carried out for this purpose. Such an analysis should answer the expectations of the company, creating a first step in qualitative method, contributing to the selection of cloud computing services corresponding to the organizational model. A second step should take place after identification of an appropriate set of cloud computing services, which leads to the question of whether the transition to a new model of data processing will bring savings in relation to the status quo. To achieve this objective, the areas that generate data processing costs should be identified including: purchase cost of equipment, license fees, maintenance of infrastructure, implementation of new functionality and many others. Subsequently, it is necessary to choose appropriate measures for the identified areas and develop a model to estimate costs.

The author, considering presented material, considers a thesis statement that for the purpose of proper selection of cloud computing service it is necessary to apply qualitative analysis, which allows comparing the costs of selected type with other data models. The particulars of the outlined method applied for selection of cloud computing services are the subject for further research.

\section{Bibliography}

[1] Allcock B. et al. - Data Management and Transfer in High Performance Computational Grid Environments [in] Parallel Computing Journal, 28(5), May 2002.

[2] Fryźewicz Z., Nikończuk D. - Windows Azure wprowadzenie do programowania $w$ chmurze. Helion, Gliwice 2012.

[3] Greaver Junior M.F. - Strategic Outsourcing. A Structured Approach to Outsourcing Decisions and Initiatives. AMACOM, New York 1999.

[4] Joszczuk-Januszewska J. - Analiza możliwości przetwarzania siatkowego $i$ jego zastosowania $w$ wybranych przedsiębiorstwach. Prace Wydziału Nawigacyjnego Akademii Morskiej w Gdyni, No. 22/2008.

[5] Lagowski J. - Cloud Computing - Co to jest?, XVI Konferencja PLOUG, Kościelisko 2010.

[6] Łapiński K., Wyżnikiewicz B. - Cloud Computing wpływ na konkurencyjność przedsiębiorstw i gospodarkę Polski, Warszawa 2011. 
[7] Mateos A. Rosenberg J. - Chmura obliczeniowa rozwiqzania dla biznesu. translated by Walkowska Justyna, Gliwice: Helion, 2011.

[8] Raport: cloud computing: elastyczność, efektywność, bezpieczeństwo. Instytut Badańnad GospodarkąRynkowa, 2011.

[9] Stasiak A., Skowroński Z. - Wirtualizacja - kierunek rozwoju platform n-procesorowych. Przegląd telekomunikacyjny, Vol. LXXXI, No. 6/2008.
[10] Badger L., Grance T., Patt-Corner R., Voas J. Draft Claud Computing and Recommendations. National Institute of Standards and Technology (NIST), 2011.

[11] www.gartner.com

[12] www.tiger.com.pl

[13] www.itpedia.pl

[14] www.uw.edu.pl

[15] www.wikipedia.org 